\title{
De vazios e pontes: referenciação aplicada à divulgação da ciência ${ }^{1}$
}

\section{On shifts and bridges: reference applied to scientific popularization}

Ana Fukui*

*Universidade do Vale do Rio do Sinos (Unisinos), São Leopoldo, Rio Grande do Sul / Brasil anafukui@hotmail.com

RESUMO: O objetivo deste artigo é aplicar os conceitos da Linguística para evidenciar uma compreensão epistemológica de textos de divulgação da ciência. Como fundamentação teórica, utilizaram-se conceitos da referenciação, tais como linguagem comum e científica, e a ideia de negociação entre leitor e autor. O corpus de estudo são dois artigos da revista Ciência Hoje do Ano Internacional da Química escritos por cientistas. Os resultados obtidos confirmaram a hipótese inicial de que existem marcas no texto que podem ser compreendidas como uma negociação entre o senso comum e o conhecimento científico.

PALAVRAS-CHAVE: divulgação da ciência; referenciação; Ciência Hoje.

ABSTRACT: This academic paper aims to apply the concepts of Linguistics in order to evidence an epistemological understanding of scientific popularization articles. Concepts of reference, such as ordinary and scientific language, were used as theoretical foundation, as well as the idea of negotiation between reader and author. The corpora analyzed comprise two articles written by scientists from the magazine Ciencia Hoje of the International Year of Chemistry. The results confirmed the initial hypothesis that there were marks in the text that could be understood as a negotiation between common sense and scientific knowledge.

KEYWORDS: scientific popularization; reference; Ciência Hoje.

\footnotetext{
1 Artigo resultante de pesquisa de doutorado em Linguística Aplicada, realizado na Universidade do Vale do Rio do Sinos (Unisinos) e orientado pela Profa. Dra. Maria Eduarda Giering.
} 


\section{Introdução}

A divulgação da ciência é um tema que pode ser abordado por muitos ângulos diferentes. Existe a parte prática, em que são realizadas ações de popularização da ciência em locais de aprendizagem formal e informal, tais como museus, feiras de ciências, peças de teatro, revistas, colunas de jornais, programas para televisão, blogs sobre ciência, canais no You'Tube etc. Todas essas atividades lidam com o desafio de fazer com que os conteúdos de ciência sejam adaptados a diferentes suportes, públicos e gêneros textuais. Muitos desses procedimentos foram estudados por Calsamiglia (2003) e definidos como recontextualização, isto é, o texto produzido traz uma série de indícios do texto original, mas sofre modificações em sua estrutura e vocabulário, definidas pelo autor de acordo com o público a que se destina e o meio de comunicação utilizado.

Outros estudiosos da Linguística analisaram textos de divulgação científica em jornais e revistas de grande circulação. Nessa direção tem-se, por exemplo, o trabalho de Moirand (2000), no qual é investigada a produção da imprensa francesa. O artigo de Beacco et al. (2002) faz uma síntese das pesquisas realizadas no mesmo país segundo a análise de discurso francesa. Na Espanha, Calsamiglia e Van Dijk (2004) realizaram um estudo semântico de 42 textos publicados no jornal espanhol El Pais de diferentes gêneros, em torno da mesma temática: o sequenciamento do genoma humano.

Pesquisas dentro desse tema também foram feitas no Brasilcom diferentes aportes teóricos. As revistas Ciência Hoje, Revista Fapesp e Superinteressante foram analisadas por Grillo (2013) a partir das proposições bakhtinianas exclusivamente; notícias on-line em português e inglês dos sites da BBC News, Scientific American, Nature e ABCScience foram avaliadas em uma perspectiva interdisciplinar que utilizou conceitos da Sociorretórica e da Linguística Sistêmico-Funcional (MOTTA-ROTH; SCHERER, 2012).

Existe também um conjunto de estudos que utilizaram a linguística textual e a semiolinguística como fundamentos para lidar com tópicos específicos da divulgação da ciência, tais como: infográficos (SOUZA, 2013), divulgação científica para crianças (IRACET; LUNKES, 2011) e o uso de anáforas (GIERING, 2012). É nesse campo que este artigo se situa. Para isso, escolheu-se como objeto de estudo a revista Ciência Hoje. Essa escolha se justifica pela proposta da revista de trazer cientistas como autores de textos voltados para o grande público e não para seus pares. 
O objetivo da análise a ser realizada é aplicar os conceitos da Linguística para evidenciar uma compreensão epistemológica de textos de divulgação da ciência. Nesse sentido, utilizaram-se alguns temas associados à Linguística do Texto, tais como: a referenciação (MONDADA, 2002), a fim de compreender o que vem a ser um texto de divulgação científica; e a ideia de negociação (CAVALCANTE; CUSTÓDIO FILHO; BRITO, 2014), para lidar com os diferentes pontos de vista presentes no texto: o do leigo e o do cientista. A epistemologia da ciência na abordagem de Bachelard (1996) permite mostrar a complementaridade desses enfoques na construção do conhecimento científico em um dado texto.

\section{Fundamentação teórica}

Este trabalho parte especificamente das proposições de Mondada (2002), em que a pesquisadora mapeia questões relacionadas à referência e constrói o conceito de referenciação. Para isso, há uma inversão das questões norteadoras do tema em pauta, o que permite construir algumas hipóteses como ponto de partida:

Com efeito - no lugar de partir do pressuposto de uma segmentação a priori do discurso em nomes e do mundo em entidades objetivas, e, em seguida, de questionar a relação de correspondência entre uma e outra parece-nos mais produtivo questionar os próprios processos de discretização. Desejamos, além disso, sublinhar que, no lugar de pressupor uma estabilidade a priori das entidades no mundo e na língua, é possível reconsiderar a questão partindo da instabilidade constitutiva das categorias por sua vez cognitivas e linguísticas, assim como de seus processos de estabilização (MONDADA, 2002, p. 119).

Para explicar seu ponto de vista, Mondada (2002) traz inicialmente algumas reflexões consolidadas - como a colocação de que a linguagem consiste na ação de nomear as entidades do mundo - e as recusa peremptoriamente. Para a autora, não existe sequer a divisão entre mundo e linguagem. Desse modo, embora se reconheça a existência de categorias cognitivas e linguísticas, não há argumentos suficientes para sustentar uma linha divisória clara entre a realidade e a linguagem. Essa perspectiva se fundamenta na aceitação de que a linguagem é heterogênea, opaca, e não funciona como um reflexo especular do mundo. 
A partir do entendimento dessas condições iniciais, a autora postula que:

O problema não é mais, então, de se perguntar como a informação é transmitida ou como os estados do mundo são representados de modo adequado, mas de se buscar como as atividades humanas, cognitivas e linguísticas, estruturam e dão um sentido ao mundo. Em outros termos, falaremos de referenciação, tratando-a, assim como à categorização, como advindo de práticas simbólicas mais que de uma ontologia dada (MONDADA, 2002, p. 119).

Portanto, referenciação é a elaboração de um sentido simbólico da linguagem vinculado aos mais diversos tipos de ações humanas: as experiências socioculturais e sensório-perceptuais, juntamente com as predisposições intelectivas e afetivas. Tudo isso é determinante na forma como os falantes designam as entidades do mundo. É preciso salientar, contudo, que essa abordagem não tem a intenção de se concentrar em uma realidade existente a priori e não trata do problema de identificar "o real", tão caro à filosofia. Em vez disso, parte do princípio de que o entendimento e a significação do mundo são construídos por uma compreensão tanto cognitiva quanto linguístico-discursiva, isto é, subordinada aos arranjos comunicacionais da realidade.

Em seguida, Mondada (2002, p. 119) traz um ponto fundamental para tecer a nova abordagem: o questionamento dos "processos de discretização e de estabilização". A noção de discreto pode ser traduzida como a aceitação da ideia de uma separação entre realidade e linguagem; por outro lado, o processo de estabilização se refere ao sentido das palavras e frases que podem variar no tempo e na situação de uso,a partir da aceitação de que a construção de sentidos é uma atividade social, e não uma atividade normativa.

Dessa forma, Mondada (2002, p. 119) propõe que:

Esta abordagem implica uma visão dinâmica que leva em conta não somente o sujeito "encarnado", mas ainda um sujeito sociocognitivo mediante uma relação indireta entre os discursos e o mundo. Este sujeito constrói o mundo ao curso do cumprimento de suas atividades sociais e o torna estável graças às categorias - notadamente às categorias manifestadas no discurso.

Nessa sua fala, finalmente, a autora explicita uma das hipóteses essenciais em sua proposição teórica: o discurso como um espaço de 
manifestação das categorias que permitem observar a referenciação ao se considerar o homem e a linguagem em situações reais. Um dos componentes imprescindíveis à referenciação proposto por Mondada (2002, p. 119) é o conceito de instabilidade, entendido como "uma dimensão intrínseca do discurso e da cognição". Assim, a autora constata que as imperfeições na língua manifestadas durante o seu uso não são necessariamente equívocos, erros ou falta de precisão, mas indícios de fenômenos essenciais da linguagem que devem ser investigados como tais, sem a necessidade de uma avaliação negativa.

Portanto, Mondada (2002, p. 120) entende que "as categorias utilizadas para descrever o mundo mudam, por sua vez, sincrônica e diacronicamente: quer seja em discursos comuns ou em discursos científicos, elas são múltiplas e inconstantes; são controversas antes de serem fixadas normativa ou historicamente". São identificadas nesse trecho algumas das condições que influenciam as transformações na linguagem do dia a dia: as mudanças que acontecem com o passar do tempo e aquelas que ocorrem em um dado momento pela influência simultânea de fatores múltiplos. Assim, se estabelece um afluxo de sentidos diversos antes da consagração de um ou mais significados por seus usuários. Toda essa construção envolve o nível cognitivo, psicológico, discursivo e textual dos falantes.

Outro dado destacado pela autora é a diferença entre o que ocorre na linguagem natural e na linguagem científica. Para ela,

Se podemos imaginar facilmente que os objetos naturais possam ser desestabilizados e mudados por decisões políticas ou administrativas, é menos corrente considerar as controvérsias científicas como procedendo de um modo similar em sua estabilização de etiquetas verídicas de objetos psíquicos. Se considerarmos a ciência como um raciocínio prático, histórica e socialmente situada, perceberemos que ela é atravessada pelos problemas frequentes de instabilidade categorial: pode-se até ler sua história como uma sucessão de afirmações e informações de categorias pertinentes (MONDADA, 2002, p. 122).

Anteriormente, a autora descreveu e identificou o processo de estabilização da linguagem cotidiana e seus mecanismos. Nesse trecho, Mondada (2002) procura averiguar as condições do mesmo processo na instância da ciência. Para isso, observa historicamente as categorias de uma disciplina, constatando que ocorrem alterações ao longo do tempo que muitas vezes divergem de conhecimentos precedentes. 
O reconhecimento de que existe, dentro da referenciação, uma descrição precisa de como os significados são construídos na linguagem comum e de que esse procedimento é diferente na linguagem da ciência é que leva à pergunta: como situar e descrever a linguagem usada na divulgação da ciência? Ou seja: será que ela está mais próxima da linguagem cotidiana ou da linguagem científica?

Desde o primeiro instante, é possível intuir que a divulgação da ciência ocupa um espaço entre os dois extremos constatados; isto é, como menciona o título deste artigo, a divulgação da ciência procura construir pontes sobre o vazio existente entre a linguagem do dia a dia e a linguagem da ciência, segundo as definições da referenciação.

Para trazer argumentos que sustentem essa proposição, consideramse dois estudos anteriores: o primeiro deles (ZAMPONI, 2005) analisou as estratégias usadas pelos jornalistas para construir a referência em dois veículos midiáticos: o jornal Folha de S. Paulo e o boletim informativo da Fapesp. Um dos dados mais significativos apresentados por essa autora é o pressuposto adotado em seu trabalho:

Assumo, assim, que a produção discursiva no gênero de popularização da ciência, considerando a mudança de contexto que necessariamente ocorre na transferência do conhecimento produzido por especialistas e não especialistas, deixa marcas no texto bem como que há traços que são observáveis e acessíveis à análise linguística (ZAMPONI, 2005, p. 177).

Isto é, um texto de divulgação científica possui indícios textuais detectáveis que mostram dois fenômenos associados e concomitantes: a mudança discursiva e a alteração do público a quem se destina. $\mathrm{Na}$ mudança discursiva, o que é dito na escrita acadêmico-científica tem que ser modificado para se tornar um texto de popularização. Ou seja, a mudança de contexto impõe uma alteração no modo de organização discursiva para se adaptar à nova situação comunicativa de acordo com um processo midiatizado. Já no segundo fenômeno, há a transposição de um público especialista, pertencente ao contexto acadêmico, para um público genérico, de forma que a transformação da identidade do destinatário, do cientista para o leigo, influencia o comportamento discursivo do produtor do texto. Para que esses procedimentos ocorram de maneira satisfatória, é preciso haver uma recontextualização. Conforme Zamponi (2005, p. 178, grifo no original): "produzir um texto de popularização da ciência significa 
recontextualizar uma fonte de modo que ela seja compreensível e relevante para diferentes tipos de ouvintes/leitores, em um contexto que, embora previsível, difere do contexto da fonte original".

Com essa afirmação, é possível definir como condição indispensável à popularização da ciência a transformação de informações complexas em informações acessíveis ao público não especializado, por meio de diferentes estratégias textuais e pela retomada de um mesmo conceito ao longo do texto, reelaborado de formas distintas.

Em resumo, no trabalho de Zamponi (2005) é discutida a forma como ocorre a recontextualização do discurso científico para o discurso de popularização da ciência. A pesquisadora também descreve algumas táticas utilizadas pelos jornalistas na realização desse procedimento, e evidencia um pressuposto adotado neste trabalho: existe um conjunto de indícios comprovadores das mudanças que ocorrem na recontextualização. Esses dados são importantes porque trazem como pano de fundo o reconhecimento de que a linguagem do meio científico difere da linguagem cotidiana, como apontado anteriormente por Mondada (2002).

Na segunda pesquisa, Zandonai (2012) observou artigos da revista Ciência Hoje das Crianças, evidenciando o uso intenso de hiponímias e hiperonímias como estratégias de referenciação presentes nos textos. Os resultados obtidos mostraram que:

O hipônimo e o hiperônimo compartilham traços conceituais e, portanto, a elucidação de suas dimensões e propriedades agrega a recuperação das noções do senso comum e facilitam o ajustamento do leitor às proposições científicas. [...] Essa relação, ao atender aos sistemas de compreensão do senso comum ao mesmo tempo em que atende às estruturas cognoscitivas da comunidade científica, supõe que o locutor se adeque a duas instâncias diferentes (ZANDONAI, 2012, p. 152-153).

As conclusões do autor indicam a existência de duas instâncias, conforme prevê a teoria da referenciação, que são colocadas em contato no texto de divulgação científica por meio das anáforas: o senso comum e o conhecimento científico. Nessa situação, o uso de hipônimos e hiperônimos faz com que ocorra a manutenção das características significativas do objeto de discurso, o que conduz o leitor à transformação de seus conceitos iniciais em direção às definições da comunidade acadêmica. Para isso, há um "movimento que parte da expressão comum e desemboca em termos especializados" (ZANDONAI, 2012, p. 154). O texto, portanto, é 
construído de maneira a evocar os conhecimentos de senso comum do leitor, e, a partir deles, construir uma série de ações linguísticas que o conduzam a uma forma mais elaborada de conhecimento, mais próxima do que são as proposições da ciência.

Os dois estudos citados procuram demonstrar que os textos de divulgação científica se situam entre a elaboração cotidiana da linguagem, feita no uso dos falantes, e a elaboração científica, na qual há sempre a necessidade de estabelecer significados de antemão. No entanto, as proposições dos estudos sobre referenciação normalmente não preveem essa categoria do "meio do caminho". Isto é, de acordo com Mondada (2002), as discussões sobre o tema lidam com a construção dos objetos no mundo de forma geral ou na instância acadêmica, mas não com o texto que realiza a ligação entre o conhecimento científico e a realidade cotidiana. Daí a necessidade de uma ponte entre essas duas categorias.

Neste artigo, adotam-se os recortes teóricos descritos. Assim, acata-se o pressuposto de que as ações, da mesma forma que as convicções, opiniões e representações sobre dado assunto do produtor textual são marcadas textualmente. Por fim, valida-se a hipótese de que existem conhecimentos em duas instâncias - senso comum e ciência- presentes no texto.

Para continuar esse percurso, é fundamental ainda o diálogo com outros saberes de modo a propor um modelo mais amplo para a análise das estratégias textuais presentes na divulgação da ciência.

Nesse sentido, buscaram-se subsídios na epistemologia da ciência, conforme Bachelard (1996) em seu livro A formação do espírito científico. Nesse trabalho, o autor descreve como o conhecimento sobre a ciência é organizado em termos psicológicos, identificando uma série de etapas do aprendizado científico descritas como obstáculos epistemológicos: "é no âmago do próprio ato de conhecer que aparecem, por uma espécie de imperativo funcional, lentidões e conflitos" (BACHELARD, 1996, p. 17). Ou seja, segundo o autor, o aprendizado em ciências acontece entremeado por confusões internas causadas pelo confronto entre o que já se sabe e o que se está aprendendo. E essa agitação é inerente ao próprio processo de aquisição de conhecimento.

Nesse modelo epistemológico, um dos pontos de partida é o acúmulo de experiências e observações, ainda que desorganizadas e pouco elaboradas, as quais são denominadas senso comum ou "experiência primeira, a experiência colocada antes e acima da crítica” (BACHELARD, 1996, p. 29). 
Essas percepções são adquiridas na vivência cotidiana e fazem parte tanto do repertório individual quanto do conjunto de saberes compartilhados socialmente - algumas refletem concepções formadas pela observação direta de experiências, outras são conhecimentos científicos que se transformaram em senso comum.

Para Bachelard (1996), os problemas e obstáculos epistemológicos configuram-se quando esses conhecimentos passam a ser a fonte da elaboração científica. Tendo isso em vista, acredita que "não se trata, portanto, de adquirir uma cultura experimental, mas sim de mudar uma cultura experimental, de derrubar os obstáculos já sedimentados pela vida cotidiana” (BACHELARD, 1996, p. 23, grifo no original). Assim, para o autor, não basta observar os fenômenos e, a partir deles, elaborar teorias e hipóteses: é preciso lutar contra a explicação fácil do senso comum e o deslumbramento dos acontecimentos, para que se possa, então, tecer críticas, fazer desconstruções e caminhar em direção a elaborações complexas, que se aproximem do fazer científico. No entanto, o aprendizado na forma de pensar cientificamente não implica o abandono das concepções cotidianas. O que ocorre, em vez disso, é a estruturação de novos patamares de conhecimento que vão delimitar o senso comum, sem que aconteça uma substituição incondicional. Isso significa que o senso comum permanece mesmo com o aprendizado científico.

O entendimento dos argumentos epistemológicos, juntamente com os fundamentos da referenciação, abre a possibilidade de propor uma nova forma de análise dos textos de divulgação científica. Nessa perspectiva, fazse uso da ideia de negociação, numa visão discursiva:

a negociação é um princípio constitutivo da linguagem, por isso faz parte de qualquer situação de interação por meio dos textos. Nos textos em que os interlocutores parecem não atuar diretamente na produção, por exemplo, nas situações de modalidade escrita em que os sujeitos não respondem diretamente à fala do outro, a negociação ocorre como antecipação ou projeção das atitudes dos prováveis destinatários (CAVALCANTE; CUSTÓDIO FILHO; BRITO, 2014, p. 38).

Nas interações presenciais, o conceito de negociação na linguagem é compreendido de forma quase intuitiva, já que os ajustes ocorrem todo o tempo. Nesse caso, concordâncias e dissonâncias são articuladas na troca entre os participantes. Em textos escritos a negociação é compreendida de outra forma, uma vez que não existe a presença física daqueles que integram 
o ato comunicativo. Nesse contexto, a afirmativa de Cavalcante, Custódio Filho e Brito (2014) evidencia que a negociação se dá pela maneira como o texto é organizado, já que há uma projeção do público ao qual ele se destina. Ou seja, o leitor é delineado, ainda que de forma incompleta, visto que não é possível produzir um texto sem considerar seu destinatário.

A ideia de negociação ganha consistência ao ser examinada de acordo com um dos pressupostos fundamentais da linguagem: o dialogismo segundo Bakhtin. Sobre o tema, Fiorin (1994, p. 29) afirma que:

Bakhtin, durante toda sua vida, foi fiel ao desenvolvimento de um conceito: o de dialogismo. Sua preocupação básica foi a de que o discurso não se constrói sobre o mesmo, mas se elabora em vista do outro. Em outras palavras, o outro perpassa, atravessa, condiciona o discurso do eu.

Na declaração anterior, Fiorin (1994) apresenta os princípios da noção bakhtiniana de dialogismo, que estabelece como hipótese inicial a presença de uma influência externa em toda ação comunicativa. Ou seja, a linguagem é demarcada tanto pelo que se deseja falar como pelo reconhecimento de um destinatário em particular ao qual se direciona essa fala.Não há, desse modo, fala individualizada, pessoal, isolada do mundo - toda palavra estabelece uma relação entre sujeitos. Ou ainda, como propõe Barros (1994, p. 2-3):

O dialogismo decorre da interação verbal que se estabelece entre o enunciador e o enunciatário, no espaço do texto. [...] Para o autor [Bakhtin], só se pode entender o dialogismo interacional pelo deslocamento do conceito de sujeito. O sujeito perde o papel de centro e é substituído por diferentes (ainda que duas) vozes sociais, que fazem dele um sujeito histórico e ideológico.

O texto materializado, de acordo com Barros (1994), concretiza um vínculo entre interlocutores expresso na forma de palavras e subordinado ao contexto histórico, social e cultural. Os registros escritos, assim, não são somente uma expressão individual,mas se transformam em um espaço de contato entre aqueles que o produzem e aqueles a quem se dirigem, manifestando-se de muitas formas diferentes tais como: dissuadir, convencer, explicar etc.

$\mathrm{Na}$ referenciação, um dos objetivos do produtor textual é encontrar maneiras de partilhar os objetos do mundo com o leitor, ao transformar esses referentes em objetos de discurso. De acordo com o princípio de dialogicidade, esses objetos não são únicos e previamente definidos, mas se 
modificam ao longo do texto, de acordo com as características da situação comunicativa e com o diálogo que se espera em tal situação. Dessa forma, o pressuposto de dialogicidade bakhtiniano estabelece que esse movimento seja feito em função do que se diz e para quem se diz algo:

Quando se produzem e compreendem textos, os sujeitos participam ativamente da interação, de modo que estão sempre negociando os sentidos construídos. O processo é amplamente dinâmico, porque permite modificações com o desenrolar das ações. A construção referencial nada mais é que o resultado dessa negociação (CAVALCANTE; CUSTÓDIO FILHO; BRITO, 2014, p. 35).

De acordo com a citação anterior, os autores sujeitam a produção e a compreensão textual às mesmas ações, evidenciando que esses dois momentos exigem a atuação dos interlocutores, o que estabelece um vínculo entre eles concretizado no texto. O elo constituído é flexível e os conduz a elaborações múltiplas de sentido. Essas construções ocorrem com o desenrolar do texto e levam a uma ordenação de significado, isto é, à construção referencial, que reflete um deslocamento tanto do produtor quanto do leitor para chegar a um entendimento comum. Por isso, tal fenômeno é chamado por Cavalcante, Custódio Filho e Brito (2014) de negociação.

Nos textos de divulgação científica, pelo menos duas vozes estão presentes: a voz do leitor, que, como leigo, traz o senso comum calcado em percepções desordenadas e irrefletidas; e a voz do cientista, amparado pela teoria e por métodos rigorosos que exigem conceitos precisos. Assim, o texto de comunicação da ciência, dentro do pressuposto de dialogicidade, traz marcas indiciais da presença dessas duas vozes que denotam uma negociação, um entendimento entre as partes envolvidas - o leitor e o cientista.

Esse procedimento acontece ao longo do texto juntamente com a estruturação do objeto de discurso. Esse conceito foi explorado por muitos autores, como Koch, Morato e Bentes (2005), Cavalcante, Rodrigues e Ciulla (2011) e Cavalcante e Lima (2013). Neste estudo, destacam-se, contudo, os pressupostos apresentados por Koch e Marcuschi (1998), que sintetizam as discussões sobre a referenciação e propõem que o objeto de discurso é uma construção textual subordinada às suas condições de produção. Dessa forma, pode-se entender que a realidade estabelece os referentes, isto é, 
os elementos que compõem dada situação, mas sua existência textual só é possível enquanto objetos de discurso.

Uma vez que o objeto de discurso está instituído no texto, o autor o acessa de distintas maneiras com o objetivo de preservar ou transformar seu sentido, seja por meio de acréscimo ou modificação de informações sobre o tema. Para isso, acontece a retomada, isto é, a continuidade do núcleo referencial; ou a remissão, ao trazer os indícios textuais para a construção de seu significado no cotexto.

Dessas formulações, a que se destaca na análise da referenciação e da orientação argumentativa é a ação de remissão sob a forma de expressões nominais. Assim, Koch, Morato e Bentes (2005, p. 35) afirmam que:

Fundamentada, pois, no pressuposto anteriormente esboçado de que a remissão textual, em particular quando realizada por meio de descrições ou formas nominais, constitui uma atividade de linguagem por meio da qual se (re)constroem objetos-de-discurso, tenho por objetivo evidenciar que uma de suas funções textual-interativas específicas é a de imprimir aos enunciados em que se inserem, bem como ao texto como um todo, orientações argumentativas conformes à proposta enunciativa do seu produtor.

O trecho anterior demarca uma das condições fundamentais da teoria da referenciação: a observação das descrições e das formas nominais como indicadores de determinado ponto de vista. Nesse processo, o objeto de discurso é destacado e qualificado em diversos instantes ao longo do texto, na medida em que as expressões usadas trazem características escolhidas e atribuídas pelo locutor. Esses requisitos são resumidos com a seguinte colocação:

As expressões nominais remissivas funcionam como uma espinha dorsal do texto, que permite ao leitor/ouvinte construir, com base na maneira pela qual se encadeiam e remetem, umas às outras, um "roteiro" que irá orientá-lo para determinados sentidos implicados no texto e, consequentemente, para as leituras possíveis que, a partir dele, se projetam (KOCH; MORATO; BENTES, 2005, p. 46).

Portanto, é preciso ir além da observação isolada das expressões nominais remissivas e considerar que essas se organizam e organizam o texto em toda a sua extensão. Com isso, essas expressões são capazes de estabelecer e sustentar uma perspectiva particular do objeto de discurso presente em um texto. 
Essas condições analíticas podem ser mais abrangentes de acordo com as proposições de Cavalcante, Custódio Filho e Brito (2014, p. 45):

no texto, a construção referencial se dá por meio de outros substratos, além das expressões utilizadas para que se identifique um dado referente. Vemos, assim, que a representação de um referente não se pauta apenas pelas expressões referenciais utilizadas para designá-lo. Aliás, deve-se salientar que essa construção nem mesmo chega a depender exclusivamente de sintagmas nominais.

Nesse excerto, os autores indicam que a construção referencial ocorre em outros elementos do texto além dos sintagmas nominais, já que os referentes são reelaborados por palavras e expressões presentes no cotexto. Portanto, para delinear o significado do referente, devem-se observar, também, as predicações a ele relacionadas. Essa nova premissa levanta uma série de possibilidades de observação da organização textual e da orientação argumentativa, aspecto enfatizado neste trabalho.

Uma vez apresentada a forma como se pretende analisar o objeto de discurso nesta pesquisa, é necessário, ainda, entrelaçá-la com os conceitos anteriormente citados: senso comum, conhecimento científico e negociação. Assim, toma-se como uma das premissas deste trabalho, embasada na teoria da referenciação, a hipótese de que a construção do objeto de discurso da divulgação científica ocorre como uma negociação de sentido entre o senso comum, trazido pelo leitor, e o conhecimento do cientista, pertencente ao produtor textual. Esse procedimento ocorre de forma distinta na elaboração de sentido na linguagem cotidiana, porque, enquanto nesta raramente se explicita a definição dos termos, sendo seu sentido organizado pelo uso da língua, na linguagem científica os termos são definidos pela comunidade acadêmica. No entanto, o texto de popularização da ciência tem como objetivo fazer com que os objetos de discurso científico, de alguma forma, tornem-se compreensíveis à linguagem cotidiana, e, para que isso aconteça, há uma negociação de sentido entre as definições rígidas da ciência e os termos cotidianos acerca de um mesmo objeto realizada ao longo do texto.

\section{Materiais e métodos}

O corpus inicial foi formado por 18 reportagens com o tema "química" publicadas na revista Ciência Hoje, em 2011, e relacionadas ao Ano Internacional da Química. A revista Ciência Hoje tem como objetivo 
divulgar a ciência realizada no Brasil e "é voltada para um público amplo e heterogêneo” (INSTRUÇÕES para..., 2002). Além disso, os artigos são escritos por cientistas sobre as suas pesquisas, os resultados obtidos e os desdobramentos de seu trabalho na sociedade.

A construção metodológica da pesquisa exigiu critérios para selecionar uma amostra dentre as 18 reportagens e também um trecho de cada um dos textos a serem analisados. Assim, como critério de escolha dos textos, considerou-se a presença de afirmativas de senso comum que trazem o ponto de vista do leitor. Esses enunciados deveriam estar presentes no texto de introdução dos artigos, que se destacavam do corpo do texto, como mostra a Figura 1.

FIGURA 1 - Páginas iniciais do artigo (o texto analisado está indicado pelo quadrado com a seta)

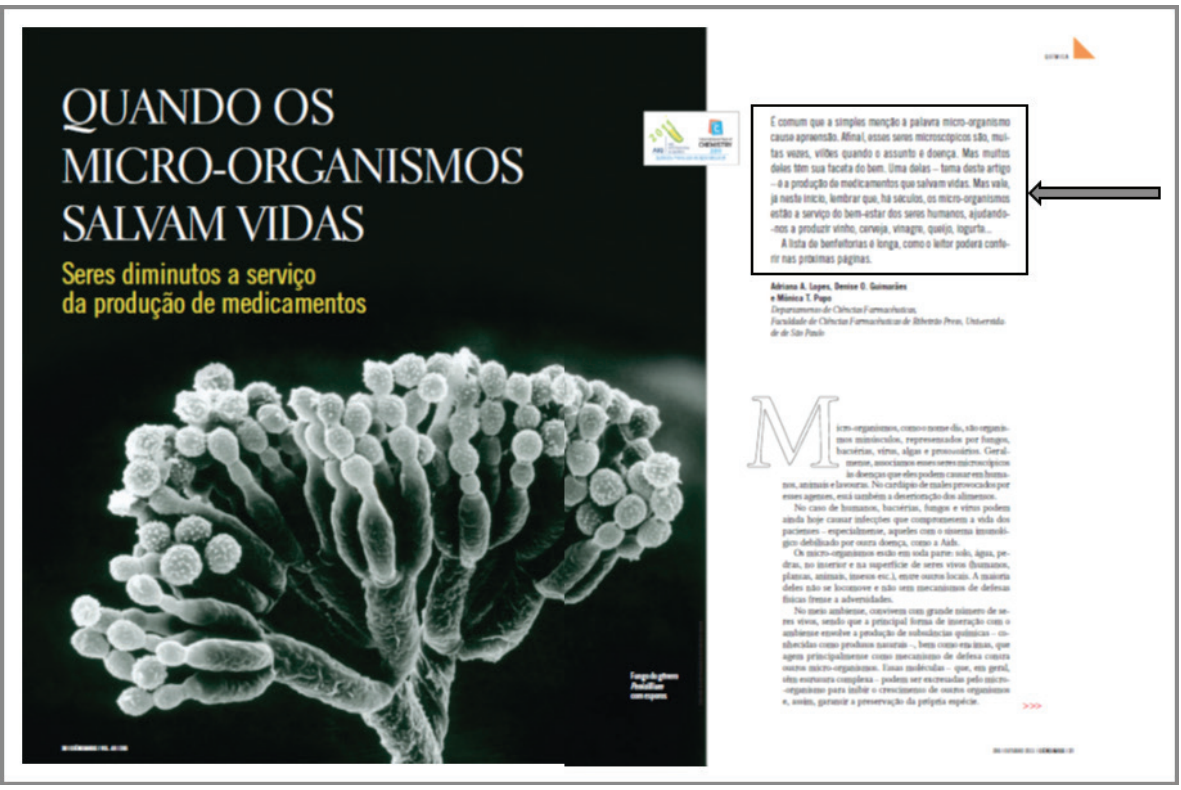

Fonte: Lopes, Guimarães e Pupo (2011).

Finalmente, para justificar a divisão do texto escolhido, usou-se a noção de segmentação textual tal como proposta por Adam (2011, p. 263, grifos no original): 
O grau de demarcação das subunidades (vamos chamá-las de segmentos textuais, sem prejulgar seu conteúdo e sua extensão) de um plano de texto ocasional varia muito. A (re)construção de partes ou segmentos que correspondem ou ultrapassam os níveis do período e da sequência é uma atividade cognitiva fundamental que permite a compreensão de um texto e, para isso, mobiliza todas as informações linguísticas de superfície disponíveis.

O autor parte da ideia de que todo texto pode ser dividido em partes que dialogam entre si. Essas partes estão presentes e são bastante marcadas em alguns gêneros, tais como textos jurídicos, receitas de bolo e notícias de jornal, assim como em gêneros mais abertos e mutáveis, como é o caso dos romances e das longas reportagens. Portanto, não existe uma regra universal para identificar o segmento textual, já que ele se configura de acordo com as escolhas do autor e com o gênero utilizado. Nesse sentido, para Adam (2011), a percepção dessas divisões é intrínseca à ação de leitura, uma vez que faz parte de todo o complexo processo de apreensão do texto. Nesse sentido, adotou-se uma divisão em segmentos textuais.

\section{Análise de dados e resultados}

As análises e os resultados são apresentados em três partes. Num primeiro momento, os segmentos são numerados e seus desdobramentos explorados de acordo com a linguística do texto, segundo as proposições de Koch $(2009,2013)$ e Koch e Elias $(2012,2016)$. Na segunda etapa, apresentam-se os resultados que evidenciam a construção do objeto de discurso e, na terceira, é exposta uma síntese da organização dos segmentos textuais. São apresentadas análises de dois textos, dos oito que compõem o todo do corpus.

\subsection{Texto 1}

A seguir é analisado o texto de introdução do artigo publicado em outubro com o título "Quando os micro-organismos salvam vidas" (LOPES; GUIMARÃES; PUPO, 2011, p. 31): 
Quando os micro-organismos salvam vidas

Seres diminutos a serviço da produção de medicamentos

[1] É comum que a simples menção à palavra micro-organismo cause apreensão. Afinal, esses seres microscópicos são, muitas vezes, vilões quando o assunto é doença. [2] Mas muitos deles têm sua faceta do bem. Uma delas - tema deste artigo - é a produção de medicamentos que salvam vidas. [3] Mas vale, já neste início, lembrar que, há séculos, os micro-organismos estão a serviço do bem-estar dos seres humanos, ajudando-nos a produzir vinho, cerveja, vinagre, queijo, iogurte... A lista de benfeitorias é longa, como o leitor poderá conferir nas próximas páginas (grifos nossos).

\subsubsection{Etapa A - Exploração dos segmentos textuais}

No título "Quando os micro-organismos salvam vidas" ocorre a introdução do objeto de discurso do texto: "os micro-organismos". O enunciado em questão inicia com o articulador textual "quando", indicador de temporalidade que evidencia, mais precisamente, um tempo exato ou pontual (KOCH; ELIAS, 2016). A presença desse termo indica, assim, uma situação específica dentre muitas possibilidades em relação aos microorganismos, que no caso é a sua atuação para preservar a existência do homem.

Na linha de apoio, há a seguinte asserção:"Seres diminutos a serviço da produção de medicamentos” (LOPES; GUIMARÃES; PUPO, 2011, p. 31, grifo nosso).

A linha de apoio traz mais detalhes sobre a proposição do título, uma vez que afirma que os micro-organismos atuam na elaboração de remédios. O objeto de discurso introduzido no título é, então, retomado pela expressão "seres diminutos".

O segmento 1, por sua vez, evidencia as concepções do senso comum sobre micro-organismos:"[1] É comum que a simples menção à palavra micro-organismo cause apreensão. Afinal, esses seres microscópicos são, muitas vezes, vilões quando o assunto é doença" (LOPES; GUIMARÃES; PUPO, 2011, p. 31, grifo nosso).

Nesse sentido, ocorre uma explicitação do sentimento associado a esses seres, seguida de um argumento introduzido pelo uso do operador "afinal", que atua como indicador de validação "quando, através de um novo ato de fala, acrescenta-se uma possível comprovação da asserção apresentada 
no primeiro" (KOCH; ELIAS, 2016, p. 136). Ou seja, o enunciado "Afinal, esses seres microscópicos são, muitas vezes, vilões quando o assunto é doença” (LOPES; GUIMARÃES; PUPO, 2011, p. 31) justifica o sentimento de apreensão descrito anteriormente ao lembrar que os micro-organismos causam várias moléstias. Essa afirmativa também é modalizada pela presença da expressão "muitas vezes", que confere uma ideia de frequência, mas também abre outras possibilidades para a ação dos micro-organismos, como se evidencia no segmento seguinte. O objeto de discurso é retomado nesse trecho pela anáfora nominal "seres microscópicos".

Já o segmento 2 afirma: "[2] Mas muitos deles têm sua faceta do bem. Uma delas - tema deste artigo - é a produção de medicamentos que salvam vidas" (LOPES; GUIMARÃES; PUPO, 2011, p. 31).

Esse segmento é marcado pelo conector argumentativo "mas", usado no início da frase para exprimir uma contrajunção. Assim, além de o conteúdo do segmento 2 refutar as afirmativas do segmento 1, ele é preponderante. Dessa forma, o período "Mas muitos deles têm sua faceta do bem" (LOPES; GUIMARÃES; PUPO, 2011, p. 31) preenche o espaço conceitual deixado no segmento 1 , por meio da modalização realizada pela expressão "muitas vezes", e associa aos micro-organismos um lado positivo. Já o enunciado "Uma delas - tema deste artigo - é a produção de medicamentos que salvam vidas" (LOPES; GUIMARÃES; PUPO, 2011, p. 31) especifica como os micro-organismos ajudam o homem.

O objeto de discurso "micro-organismos" é retomado pela expressão "muitos deles" e predicado pelo segmento "faceta do bem". $\mathrm{Na}$ frase seguinte, retoma-se "faceta do bem" pela expressão "uma delas", especificada como a "produção de medicamentos que salvam vidas".

A seguir, o segmento 3:

[3] Mas vale, já neste início, lembrar que, há séculos, os microorganismos estão a serviço do bem-estar dos seres humanos, ajudandonos a produzir vinho, cerveja, vinagre, queijo, iogurte... A lista de benfeitorias é longa, como o leitor poderá conferir nas próximas páginas (LOPES; GUIMARÃES; PUPO, 2011, p. 31).

O segmento 3 também se inicia com uma contrajunção que indica oposição à proposta apresentada no segmento 2. Nesse momento, o produtor do texto dialoga com o leitor, lembrando-o de algo que se poderia esquecer ao considerar o dito no segmento anterior: o fato de que o lado 
bom não é algo novo. O produtor lembra, assim, que os micro-organismos são utilizados de maneira produtiva pela humanidade há bastante tempo e apresenta uma lista de produtos que envolvem sua participação.

O último período retoma a enumeração de produtos obtidos pela ação dos micro-organismos, rotulando-a (KOCH; ELIAS, 2016) de "lista de benfeitorias", isto é, assumindo que existem inúmeros benefícios advindos do uso dos micro-organismos.

\subsubsection{Etapa B - Síntese dos dados obtidos sobre o objeto de discurso}

O objeto de discurso "micro-organismos", um termo técnico, é introduzido no título e retomado por duas anáforas nominais: "seres diminutos" e "seres microscópicos" (Quadro 1). Nas duas retomadas, usase o vocábulo "seres", que concretiza a existência de tais criaturas e que é modificado por termos que fornecem uma clara noção da dimensão a que se referem - muito pequenos para serem vistos a olho nu.

Na sequência, o objeto de discurso é retomado pela palavra "vilões", que o associa ao senso comum. No entanto, esse ponto de vista é logo a seguir reconstruído pela expressão "faceta do bem" e pela descrição dos produtos profícuos associados aos micro-organismos. Finalmente, recuperase o objeto de discurso inicial, relacionando-o diretamente a benefícios para o homem.

QUADRO 1 - Construção do objeto de discurso do texto 1

\begin{tabular}{|c|}
\hline micro-organismos \\
\hline seres diminutos \\
\hline seres microscópicos \\
\hline Vilões \\
\hline faceta do bem \\
produção de medicamentos \\
\hline há séculos, os micro-organismos estão a serviço do bem-estar \\
\hline benfeitorias \\
\hline
\end{tabular}

Fonte: elaborado pela autora, 2016. 


\subsubsection{Etapa C - Organização dos segmentos textuais}

O segmento 1 mostra as associações do senso comum sobre o objeto de discurso, os "micro-organismos". Já o segmento 2 contrapõe-se ao senso comum apresentado no trecho anterior, ao citar os benefícios que os microorganismos podem trazer ao homem. O segmento 3, por sua vez, apresenta alguns exemplos de produtos usados pelo homem há bastante tempo, o que traz uma perspectiva histórica (Quadro 2).

\section{QUADRO 2 - Descrição dos segmentos textuais do texto 1}

\begin{tabular}{|l|l|}
\hline Segmento 1 & $\begin{array}{l}\text { Concepções de senso comum sobre os micro-organismos: vilões, } \\
\text { doenças. }\end{array}$ \\
\hline Segmento 2 & Benefícios dos micro-organismos: produção de medicamentos. \\
\hline Segmento 3 & $\begin{array}{l}\text { Benefícios trazidos pelos micro-organismos ao longo da história da } \\
\text { humanidade: produção de vinho, cerveja, vinagre, queijo, iogurte etc. }\end{array}$ \\
\hline
\end{tabular}

Fonte: elaborado pela autora, 2016.

\subsection{Texto 2}

A seguir é analisado o texto de introdução do artigo publicado em julho com o título "A química e os perfumes: há algo no ar" (REZENDE, 2011, p. 26):

A química e os perfumes: há algo no ar

[1] Alguns cheiros nos provocam fascínio e atração. Outros nos trazem recordações agradáveis, até mesmo de momentos de nossa infância. Aromas podem causar sensação de bem-estar ou nos dar a impressão de estarmos mais atraentes... [2] É isso que buscamos ao escolher uma fragrância para uso pessoal? Será esse o significado conceitual dos perfumes ao longo da história da humanidade? [3] Nas próximas páginas, o leitor conhecerá um pouco do papel da química na busca e no desenvolvimento de substâncias aromáticas (grifos nossos).

\subsubsection{Etapa A - exploração dos segmentos textuais}

O título do texto, "A química e os perfumes: há algo no ar", apresenta o objeto de discurso "química" e acrescenta mais um elemento a ser considerado, os perfumes. Essa ação é complementada pela asserção presente 
após os dois pontos a partir do uso de um termo que evidencia indefinição: "algo". Isto é, cria-se uma expectativa ao assinalar uma presença, sem, no entanto, nomeá-la explicitamente; o enunciado em questão lembra o leitor da forma de atuação dos perfumes, que são notados em primeiro lugar pelos sentidos. Assim, há um procedimento textual que procura captar a atenção do leitor, ao recorrer à sensação olfativa.

Observe-se o segmento 1: "[1] Alguns cheiros nos provocam fascínio e atração. Outros nos trazem recordações agradáveis, até mesmo de momentos de nossa infância. Aromas podem causar sensação de bemestar ou nos dar a impressão de estarmos mais atraentes..." (REZENDE, 2011, p. 26).

O segmento 1 continua a tratar de aspectos sensoriais dos odores. Para isso, apela para a memória do leitor, ao descrever diversas situações em que os aromas tiveram importância, deixando implícito, assim, que esse tipo de experiência foi vivenciado em algum momento pelo leitor e também pelo autor. Um dado que reforça essa aproximação é o uso da primeira pessoa do plural em dois momentos distintos - "nossa infância" e "estarmos mais atraentes" -, justapondo leitor e autor.

No segmento1, o objeto de discurso "perfume" é retomado pelos vocábulos "cheiros" e "aromas". No entanto, ocorre sempre uma complementação dos termos. Assim, "cheiro" está relacionado às palavras "fascínio" e "atração"; "outros" retoma o termo "cheiros" do enunciado anterior, modificando-o por meio das expressões "recordações agradáveis" e "momentos da nossa infância"; e "aromas" é alterado pelas expressões "sensação de bem-estar" e "impressão de estarmos atraentes". Como se pode depreender do conjunto de dados apresentados, a avaliação relacionada ao objeto de discurso inicial "perfumes" está no plano emocional e sensorial. Embora o objeto "química" não seja retomado por enquanto, existe, devido ao título, uma relação anunciada entre os dois objetos de discurso colocados logo de início: "química" e "perfumes".

Já o segmento 2 explicita perguntas que a reflexão sobre os aromas pode suscitar: "[2] É isso que buscamos ao escolher uma fragrância para uso pessoal? Será esse o significado conceitual dos perfumes ao longo da história da humanidade?” (REZENDE, 2011, p. 26).

O uso de questões conduz, segundo Adam (2011, p. 254), a "uma dialogização do procedimento descritivo”, havendo assim a explicitação 
de uma interação entre leitor e autor ao serem considerados possíveis questionamentos. No caso de tal segmento, essa ação é ainda acompanhada pelo uso do tempo verbal na primeira pessoa do plural ("buscamos"), que evidencia, novamente, a proximidade entre os dois envolvidos: leitor e autor. Ou seja, as perguntas são consideradas como pertencentes a ambos.

O objeto de discurso explicitado nesse trecho, "perfumes", é retomado pelo termo "fragrância" e modificado adiante, ao serem atribuídas algumas qualidades específicas pelo uso da expressão "significado conceitual dos perfumes". Nessa situação, há a proposta de uma avaliação qualitativa que procura esclarecer apreciações sobre o assunto, e não mensurar um processo.

A seguir, observe-se o segmento 3: "[3] Nas próximas páginas, o leitor conhecerá um pouco do papel da química na busca e no desenvolvimento de substâncias aromáticas" (REZENDE, 2011, p. 26).

O segmento 3 anuncia o principal objetivo do artigo: o desenvolvimento de novas fragrâncias. Para isso, há a retomada do objeto de discurso "química", bem como a especificação dos processos envolvidos para identificar e elaborar não mais perfumes, mas "substâncias aromáticas". Assim, o sentido implícito de "química" é o de "ciência", de modo que os resultados obtidos por ela também recebem uma denominação subordinada ao conhecimento nomeado.

\subsubsection{Etapa B - Síntese dos dados obtidos sobre o objeto de discurso}

São introduzidos no título dois objetos de discurso: a "química" e os "perfumes". Ao longo do texto, o objeto de discurso "perfume" é retomado em todos os parágrafos por meio de anáforas, ao mesmo tempo em que é associado a emoções e sensações. Já o objeto de discurso "química" é retomado como um conhecimento necessário para a obtenção dos produtos que são responsáveis pelas emoções e sensações anunciadas anteriormente (Figura 2). 
FIGURA 2 - Construção do objeto de discurso do texto 2

QUIMICA PERFUMES
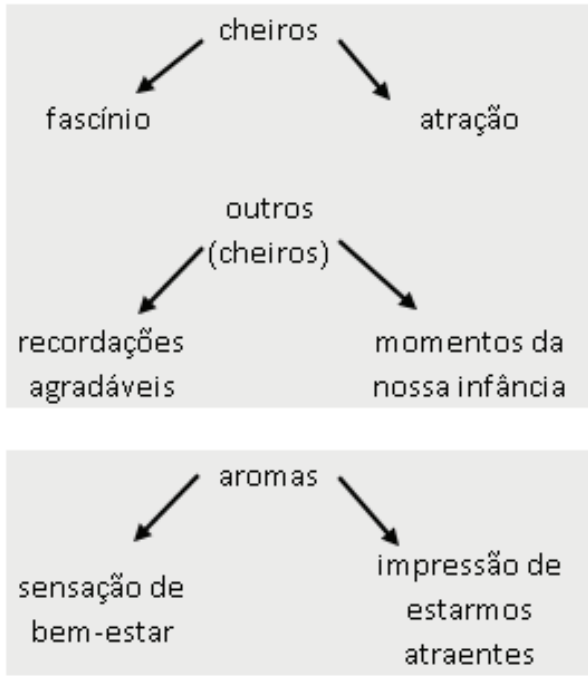

fragrância

significado conceitual dos perfumes

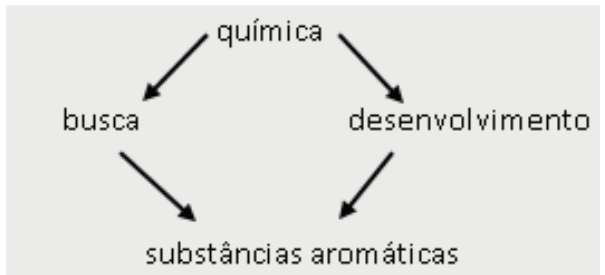

Fonte: elaborado pela autora, 2016.

\subsubsection{Etapa C - Organização dos segmentos textuais}

O segmento inicial apresenta os perfumes como algo que pertence ao cotidiano e que é, ao mesmo tempo, fonte de lembranças. Já o segmento 2 traz questionamentos sobre os elementos introduzidos anteriormente. $\mathrm{E}$ o segmento 3 define as metas do artigo e a forma como os conhecimentos da química serão utilizados. 
QUADRO 3 - Descrição dos segmentos textuais do texto 2

\begin{tabular}{|l|l|}
\hline Segmento 1 & $\begin{array}{l}\text { Descreve situações cotidianas sobre o uso do perfume e apela para } \\
\text { a memória dos leitores. }\end{array}$ \\
\hline Segmento 2 & Perguntas suscitadas pelas colocações anteriores sobre os perfumes. \\
\hline Segmento 3 & $\begin{array}{l}\text { Objetivos do artigo com a introdução dos conhecimentos da } \\
\text { química. }\end{array}$ \\
\hline
\end{tabular}

Fonte: elaborado pela autora, 2016.

Os resultados obtidos são evidências de que ocorre a negociação, ação linguística em que os sujeitos envolvidos, autor eleitor, estabelecem um vínculo. Essa ação está materializada no texto e conduz a uma determinada ordenação de sentido e à construção do referente como um objeto de discurso. Para isso, primeiramente é explorada a relação desse conceito com a construção dos objetos de discurso.

É preciso considerar, assim, que, no caso dos textos de divulgação científica da revista Ciência Hoje, duas vozes estão presentes na negociação: a do leigo, representada pelas afirmativas de senso comum e pelas analogias estabelecidas com as situações cotidianas; e a do cientista, que detém as definições da ciência. O trabalho analítico a seguir consistiu em retomar alguns trechos dos textos, identificando a presença dessas vozes com o objetivo de explicitar a ação linguística de negociação entre elas.

Esse processo de análise partiu do pressuposto de que a visão trazida pelo senso comum deve ser levada em conta de alguma forma na construção do conhecimento científico, hipótese que é subsidiada pelas proposições de Bachelard (1996) sobre os obstáculos epistemológicos, como já discutido neste estudo.

O texto 1, "Quando micro-organismos salvam vidas", iniciou-se com o reconhecimento de que os micro-organismos são lembrados pelas pessoas como causadores de doenças, como atesta o seguinte enunciado: “[é] comum que a simples menção à palavra micro-organismo cause apreensão. Afinal, esses seres microscópicos são, muitas vezes, vilões quando o assunto é doença" (LOPES; GUIMARÃES; PUPO, 2011, p. 31). No entanto, em seguida se sabe que eles têm contribuído para o desenvolvimento da humanidade de muitas formas diferentes, sendo uma delas em particular tratada no artigo: a "produção de medicamentos que salvam vidas" (LOPES; GUIMARÃES; PUPO, 2011, p. 31). O texto se encerrou lembrando que 
os micro-organismos também estão envolvidos na produção de alimentos há bastante tempo. Nesse texto, a negociação ocorre quando o ponto de vista do cientista é contraposto às afirmativas de senso comum ao serem enumerados os benefícios dos micro-organismos.

O texto 2, "A química e os perfumes...", iniciou-se com a descrição de sentimentos, emoções e memórias relacionados à percepção olfativa. Para isso, o termo "perfume" foi retomado sucessivamente por meio das seguintes expressões: "cheiros", "aromas", "fragrâncias" e "significado conceitual dos perfumes" (REZENDE, 2011, p. 26). A cada retomada, foram elencados itens que fazem parte do dia a dia das pessoas, mas que não são grandezas mensuráveis cientificamente: "fascínio", "atração", "recordações agradáveis", "momentos da nossa infância", "sensação de bem-estar" e "estar mais atraente" (REZENDE, 2011, p. 26). Ainda assim, existe a possibilidade de fazer ciência tendo em mente dados aparentemente tão subjetivos, como atestou o enunciado final dessa introdução: "o leitor conhecerá um pouco do papel da química na busca e no desenvolvimento de substâncias aromáticas" (REZENDE, 2011, p. 26). Ou seja, ocorreu uma recategorização de "cheiros" pelo termo científico "substâncias aromáticas", que representa o ponto de vista do cientista. Foi em meio a esses dois sentidos que se sucedeu a negociação entre leitor e cientista.

Como é possível perceber pelos resultados apresentados, as concepções espontâneas, elaboradas a partir da experiência direta, estão presentes e são consideradas como um ponto de vista existente e válido, sem que seja necessário qualificá-las como errôneas ou ingênuas. A negociação permitiu, assim, reconhecer a legitimidade do senso comum, concedendo espaço a esse tipo de saber, sem a necessidade de descartá-lo ou sugerir o abandono dessas concepções.

Outra forma de análise dos dois textos selecionados foi a observação de seus segmentos textuais, o que permitiu a descrição de um plano de texto. Para isso, foi preciso retomar os segmentos de cada texto, destacando em que trechos ocorreu a introdução do senso comum e do conhecimento científico, sintetizado nos Quadros 2 e 3.

Como já discutido, o segmento 1 dos dois textos analisados desenvolveu o tema anunciado no título de acordo com um ponto de vista próximo ao do leitor.

O segmento 2, por sua vez, atuou como mediador entre o ponto de vista do leitor e o da ciência. Assim, no texto 1 - "Quando os micro- 
organismos..." - o segmento 2, ao contrapor-se ao segmento 1, surpreendeu o leitor lembrando que micro-organismos também contribuem para o bem-estar da humanidade e destacou o assunto preponderante: "Mas muitos deles têm sua faceta do bem. Uma delas - tema deste artigo - é a produção de medicamentos que salvam vidas" (LOPES; GUIMARÃES; PUPO, 2011, p. 31). No texto 2, “A química e os perfumes...", o segmento 2 formulou um conjunto de perguntas partilhadas pelo leitor e o cientista: "É isso que buscamos ao escolher uma fragrância para uso pessoal? Será esse o significado conceitual dos perfumes ao longo da história da humanidade?" (REZENDE, 2011, p. 26). Essa contiguidade tornou-se ainda mais evidente pelo uso da primeira pessoa do plural. Há, portanto, a elaboração de um ponto de vista partilhado.

Como mencionado, os segmentos destacados realizam uma intervenção no texto de tal forma que conciliam dado ponto de partida, presente no segmento 1, com uma visão mais próxima da ciência. Nos casos apresentados, não ocorre a rejeição desse ponto inicial, mas sua limitação segundo condições explicitadas no próprio texto.

Uma vez que a intermediação entre senso comum e conhecimento científico foi realizada, cabe ao segmento 3 anunciar como o ponto de vista da ciência será abordado na matéria em questão. Nesse sentido, frequentemente, é usada uma expressão que anuncia os objetivos do artigo: "Nas próximas páginas...".

A estrutura do plano de texto, que pode ser resumida como uma negociação de significados entre o senso comum e o conhecimento científico, criou uma expectativa no leitor, exigindo algum tipo de resposta, de continuidade e até mesmo de certo fechamento, o que é feito no segmento 3. Todas essas ações visaram seduzir o interlocutor em dois níveis: o do texto, a fim de que a leitura continue; e o epistemológico, no intuito de instaurar possibilidades de aproximação com a ciência.

\section{Conclusões}

Esse trabalho partiu das proposições da referenciação para constatar a existência de um "vazio" entre a linguagem comum - construída pelo uso - e a linguagem científica - que sempre traz definições dos conceitos utilizados na ciência. Em seguida, tomou-se como hipótese a ideia de que a divulgação científica procura construir "pontes" entre as duas linguagens, 
comum e científica, por meio de uma negociação entre o leitor e o autor. Essa ação linguística ocorre textualmente e pode ser observada através das marcas de indiciamento e estratégias argumentativas utilizadas, devidamente assinaladas com o uso dos princípios da linguística textual, juntamente com um entendimento epistemológico do que vem a ser a ciência.

Os resultados e análises foram apresentados em três partes: em primeiro lugar, explorou-se o encadeamento dos segmentos textuais e as estratégias argumentativas; em segundo lugar, observou-se a construção do objeto de discurso; e, em terceiro lugar, descreveu-se a organização dos segmentos textuais. Esses procedimentos permitiram levantar evidências para subsidiar a abordagem teórica proposta e atender aos objetivos estabelecidos inicialmente, quais sejam: aplicar conceitos da Linguística para compreender epistemologicamente o texto de divulgação científica. Para isso, foi necessário explorar o conceito de negociação como ponto central e, a partir de seu entendimento, mostrar que os escritos dos cientistas publicados na revista partem de um conhecimento compartilhado com os leitores, para então elaborar o conhecimento científico.

Outro dado que merece destaque com a observação dos resultados obtidos acerca da construção do objeto de discurso é a abordagem peculiar dos temas escolhidos. Alguns deles são vinculados a assuntos pouco associados à ciência. O texto "Quando os micro-organismos salvam vidas" partiu do medo das pessoas para, então, mostrar o lado benéfico dos micróbios. Já o texto "A química e os perfumes: há algo no ar" se referiu a emoções e sensações para entender como é elaborado o sentido dos cheiros, particularmente os perfumes.

\section{Agradecimentos}

Agradeço à Coordenação de Aperfeiçoamento de Pessoal de Nível Superior (Capes) pela bolsa concedida durante a realização do doutorado em Linguística Aplicada, na Universidade do Vale do Rio dos Sinos (Unisinos), de que resulta este artigo. 


\section{Referências}

ADAM, J-M. A linguística textual: introdução à análise textual dos discursos. São Paulo: Cortez, 2011.

BACHELARD, G. A formação do espirito científico. São Paulo: Contraponto, 1996.

BARROS, D. L. P. Dialogismo, polifonia e enunciação. In: BARROS, D. L. P.; FIORIN, J. L. (Org.). Dialogismo, polifonia, intertextualidade: em torno de Bakhtin. São Paulo: Edusp, 1994. p. 1-9.

BEACCO, J. et al. Science in media and social discourse: new channels of communication, new linguistic forms. Discourse Studies, Thousand Oaks, v. 4, n. 3, p. 277-300, 2002. Disponível em: <https://goo.gl/rh42W2>. Acesso em: 7 jul. 2017.

CALSAMIGLIA, H. Popularization discourse. Discourse Studies, Thousand Oaks, v. 5, n. 2, p. 139-146, 2003. Disponível em: <https://goo.gl/PkBRB3>. Acesso em: 9 jan. 2017.

CALSAMIGLIA, H; VAN DIJK, T. A. Popularization discourse and knowledge about the genome. Discourse \& Society, Thousand Oaks, v. 15, n. 4, p. 369-389, 2004. Disponível em: <https://goo.gl/xrgiFn>. Acesso em: 7 jul. 2017.

CAVALCANTE, M. M.; CUSTÓDIO FILHO, V.; BRITO, M. A. P. Coerência, referenciação e ensino. São Paulo: Cortez, 2014.

CAVALCANTE, M. M.; LIMA, S. M. C. (Org.). Referenciação: teoria e prática. São Paulo: Cortez, 2013.

CAVALCANTE, M. M.; RODRIGUES, B. B.; CIULLA, A. Referenciação: sobre coisas ditas e não ditas. Fortaleza: Edições UFC, 2011.

INSTRUÇÕES para autores. Ciência Hoje, Rio de Janeiro, $1^{\circ}$ fev. 2002. Disponível em: <https://goo.gl/CdPh28>. Acesso em: 24 abr. 2018.

FIORIN, J. L. Polifonia textual e discursiva. In: BARROS, D. L. P.; FIORIN, J. L. (Org.). Dialogismo, polifonia, intertextualidade: em torno de Bakhtin. São Paulo: Edusp, 1994. p. 29-36.

GIERING, M. E. Referenciação e hiperestrutura em textos de divulgação científica para crianças. Linguagem em (Dis)curso, Tubarão, v. 12, n. 3, p. 683-710, 2012. Disponível em: < https://goo.gl/YGGDxC>. Acesso em: ${ }^{\circ}$ out. 2014.

GRILLO, S. V. C. Divulgação científica: linguagens, esferas e gêneros. 2013. 333f. Tese (Doutorado em Filologia e Língua Portuguesa) - Universidade de São Paulo, São Paulo, 2013. Disponível em: <https://goo.gl/E2AkpJ>. Acesso em: 7 jul. 2017. 
IRACET, Ê. E.; LUNKES, F. Divulgação científica midiática para crianças: as narrativas que explicam. Entrelinhas, São Leopoldo, v. 5, n. 1, p. 41-53, 2011. Disponível em: <https://goo.gl/PM4Kjn>. Acesso em: $1^{\circ}$ out. 2014.

KOCH, I. V. Introdução à Linguística Textual. São Paulo: WMF Martins Fontes, 2009.

KOCH, I. V. A Inter-ação pela linguagem. São Paulo: Contexto, 2013.

KOCH, I. V.; ELIAS, V. M. Ler e compreender. São Paulo: Contexto, 2012.

KOCH, I. V.; ELIAS, V. M. Escrever e argumentar. São Paulo: Contexto, 2016.

KOCH, I. V.; MARCUSCHI, L. A. Processos de referenciação na produção discursiva. DELTA, São Paulo, v. 14, p. 169-190, 1998. Número especial. Disponível em: < https://goo.gl/8jKQdE>. Acesso em: 4 abr. 2016.

KOCH, I. V.; MORATO, E. M.; BENTES, A. C. Referenciação e discurso. São Paulo: Contexto, 2005.

LOPES, A. A.; GUIMARÃES, D. O.; PUPO, M. T. Quando micro-organismos salvam vidas. Ciência Hoje, Rio de Janeiro, v. 48, n. 286, p. 30-35, 2011.

MOIRAND, S. Formas discursivas da difusão de saberes na mídia. Rua, Campinas, v. 6, n. 1, p. 9-24, out. 2000. Disponível em: <https://goo.gl/1EQ5rV>. Acesso em: 6 out. 2017.

MONDADA, L. Construction des objets de discours et categorisation: une approche des processus de référenciation. Tradução Mônica Magalhães Cavalcante. Revista de Letras, Fortaleza, v. 1-2, n. 24, p. 118-130, jan./dez. 2002. Disponível em: $<$ https://goo.gl/M1Ppwz>. Acesso em: 6 abr. 2016.

MOTTA-ROTH, D.; SCHERER, A. Expansão e contração dialógica na mídia: intertextualidade entre ciência, educação e jornalismo. DELTA, São Paulo, v. 28, p. 639-672, 2012. Número especial. Disponível em: <https://goo.gl/kAFbgd $\geq$. Acesso em: 7 jul. 2017.

REZENDE, C. Há algo no ar: a química e os perfumes. Ciência Hoje, Rio de Janeiro, v. 48, n. 283, p. 26-31, 2011.

SOUZA, J. A. C.Texto e discurso no infográfico de Divulgação Científica Midiática (DCM). Calidoscópio, São Leopoldo, v. 11, n. 3, p. 229-240, 2013. Disponível em: <https://goo.gl/RHf7TJ Z. Acesso em: 7 jul. 2017. 
ZAMPONI, G. Estratégias de construção da referência no gênero de popularização da ciência. In: KOCH, I. V.; MORATO, E. M.; BENTES, A. C. (Org.). Referenciação e discurso. São Paulo: Contexto, 2005. p. 169-195.

ZANDONAI, M. F. A construção de objetos-de-discurso em textos de divulgação científica midiática para crianças. Revista do Edicc, Campinas, v. 1, n. 1, p. 145-155, 2012. Disponível em: <https://goo.gl/Sx2ooC>. Acesso em: 25 maio 2016.

Data de submissão: 06/11/2017. Data de aprovação: 11/04/2018. 